\title{
PENYULUHAN KESELAMATAN DAN KESEHATAN KERJA PADA DRIVER OJEK ONLINE DI MEDAN
}

\author{
OCCUPATIONAL SAFETY AND HEALTH EDUCATION \\ ON ONLINE OJEK DRIVER IN MEDAN
}

\section{Agnes Ferusgel*, Maria Haryanti Butar-Butar, Ani Deswita Chaniago, Rupina Kanasia Situmorang}

\author{
Institut Kesehatan Helvetia, Jalan Kapten Sumarsono No. 107 Medan Sumatera Utara \\ *Email: agneslppmhelvetia@gmail.com
}

(Diterima 27-08-2021; Disetujui 15-09-2021)

\begin{abstract}
ABSTRAK
Penyuluhan merupakan salah satu metode pendidikan kesehatan yang sederhana. Selain itu, metode penyuluhan juga efektif dalam upaya penyampaian informasi secara cepat kepada kelompok sasaran. Salah satu kelompok pekerja informal yang cukup trend saat ini adalah menjadi driver ojek online. Hasil analisis lapangan menunjukkan bahwa banyak driver online yang mengejar target pekerjaan, mereka rata-rata mengalami kelelahan dan nyeri pinggang. Mereka juga tidak memperdulikan waktu kerja, sehingga pola hidup mereka tidak teratur mulai dari pola makan hingga pola tidur. Metode dalam penyuluhan ini menggunakan metode ceramah dan menyampaikan tentang keselamatan dan kesehatan kerja meliputi faktor bahaya kerja pada driver ojek online, menjelaskan ergonomi dalam berkendara, dan kiat-kiat aman berkendara untuk mencegah risiko penyakit akibat pekerjaan. Pengabdian dilakukan kepada 20 orang driver ojek online yang bersedia mengikuti serangkain acara yang telah ditetapkan. Rangkaian acaranya antara lain pengisian kuesioner, pemberian informasi, pengisian kuesioner yang kedua dan melakukan pemeriksaan kadar gula darah bagi driver yang ingin dicek saja. Berdasarkan hasil dari kuesioner yang didalamnya terdiri atas pertanyaan pengetahuan dan sikap mengenai keselamatan dan kesehatan kerja didapatkan ada peningkatan pengetahuan dan sikap sesudah dilakukan penyuluhan. Sehingga, penyuluhan K3 ini berhasil dalam meningkatkan pengetahuan dan sikap driver ojek online agar nanti sadar sehingga secara mandiri dapat melindungi diri mereka dari potensi bahaya pekerjaan. Bagi driver ojek online diharapkan dapat menerapkan pengetahuan dan sikap sehingga dalam dapat bekerja dengan aman dan selalu tetap sehat.
\end{abstract}

Kata kunci : Penyuluhan, Ceramah, Driver, Ojek Online, Keselamatan dan Kesehatan Kerja

\begin{abstract}
Counseling is a simple method of health education. In addition, the extension method is also effective in delivering information quickly to the target group. One group of informal workers that is quite a trend today is to become an online motorcycle taxi driver. The results of field analysis show that many online drivers who pursue work targets, they experience fatigue and low back pain on average. They also don't care about working hours, so their lifestyle is irregular starting from eating patterns to sleeping patterns. The method in this counseling uses the lecture method and conveys about occupational safety and health including occupational hazard factors for online motorcycle taxi drivers, explaining ergonomics in driving, and safe driving tips to prevent the risk of occupational diseases. The service was carried out to 20 online motorcycle taxi drivers who were willing to take part in a series of predetermined events. The series of events include filling out questionnaires, providing information, filling out the second questionnaire and checking blood sugar levels for drivers who only want to be checked. Based on the results of the questionnaire which consisted of questions about knowledge and attitudes regarding occupational safety and health, it was found that there was an increase in knowledge and attitudes after counseling. Thus, this K3 counseling was successful in increasing the knowledge and attitudes of online motorcycle taxi drivers so that they would later be aware so that they could independently protect themselves from potential occupational hazards. Online motorcycle taxi drivers are expected to be able to apply knowledge and attitudes so that they can work safely and always stay healthy. .
\end{abstract}

Keywords: Counseling, Lectures, Drivers, Online Ojek, Occupational Safety and Health 


\section{PENDAHULUAN}

Berdasarkan ILO (International Labour Organization) tahun 2013, setiap tahun terjadi 2,3 juta kematian yang disebabkan oleh kecelakaan kerja dan penyakit akibat kerja. Data tersebut juga menyebutkan bahwa 2 juta kematian terjadi disebabkan oleh penyakit akibat kerja, di Indonesia terdapat 428.844 kasus penyakit akibat kerja (Kalalo, 2016). Sementara data BPJS Ketenagakerjaan mencatat terjadinya 8.900 kasus kecelakaan kerja (Salindeho, Kawatu, \& Joseph, 2017).

Keselamatan kerja merujuk pada Undang-undang No 1 tahun 1970 menerangkan bahwa keselamatan kerja merupakan keselamatan yang bertalian dengan mesin, pesawat, alat kerja, bahan dan proses pengolahan, landasan kerja dan lingkungan kerja serta caracara melakukan pekerjaan dan proses produksi (RI, 1AD).

Kesehatan dan Keselamatan Kerja (K3) merupakan upaya untuk menciptakan suasana bekerja yang aman, nyaman dan mencapai tujuan yaitu produktivitas setinggitingginya (Dwi Lestari, 2018). K3 sangat penting untuk dilaksanakan pada semua bidang pekerjaan. Smith dan Sonesh mengemukakan bahwa pelatihan K3 mampu menurunkan risiko terjadinya kecelakaan kerja (Burke et al., 2011). Upaya pemerintah dalam melindungi masyarakat kerja sudah sejak lama dilakukan yaitu dengan menerbitkan Undang-Undang RI Nomor 1 Tahun 1970 tentang keselamatan kerja, tetapi proses pelaksanaanya masih belum sesuai dengan harapan.

Salah satu kelompok pekerja informal yang cukup trend saat ini adalah menjadi driver ojek online. Di Kota Medan sendiri driver ojek-online sudah mencapai 2.000 pengemudi. Pekerja sektor informal juga berhak mendapat perlindungan agar terhindar dari penyakit akibat kerja atau terjadinya kecelakaan kerja, karena di setiap tempat kerja terdapat bahaya/risiko yang dapat menyebabkan gangguan kesehatan yang berakibat kecacatan dan kematian.

Hasil analisis lapangan yang di lapangan menunjukkan bahwa banyak driver online yang mengejar target pekerjaan mereka rata-rata mengalami kelelahan mereka juga tidak memperdulikan waktu kerja sehingga pola hidup mereka tidak teratur mulai dari pola makan hingga pola tidur sehingga dapat menyebabkan penurunan derajat kesehatan pekerja (Ferusgel, Masni, \& Arti, 2019). Penurunan derajat kesehatan pekerja terlihat dari seringnya mereka mengalami sesak nafas, sering batuk, masuk angin dan mengalami kesusahan tidur. Tidak hanya itu saja, mereka juga mengalami kelelahan. Bentuk kelelahan yang mereka rasakan seperti denyut nadi bergetar lebih cepat, sesak nafas, lemas dan 
mudah lapar. Kejadian lain yang pernah mereka alami adalah kecelakaan akibat kurang konsentrasi dan juga mengantuk.

Upaya dalam meningkatkan keselamatan dan kesehatan kerja pada driver ojek online salah satunya dengan penyuluhan. Penyuluhan merupakan suatu intervensi komunikasi yang diselenggarakan untuk menimbulkan perubahan kualitas perilaku secara sukarela bagi kesejahteraan masyarakat (Afrianto, 2014).

Penyuluhan merupakan salah satu metode pendidikan kesehatan yang sederhana. Selain itu, metode penyuluhan juga efektif dalam upaya penyampaian informasi secara cepat kepada kelompok sasaran (Notoatmodjo, 2007). Penyuluhan K3 sebagai penambahan pengetahuan dan kemampuan seseorang melaui teknik praktik atau instruksi dengan tujuan mengubah atau mempengaruhi perilaku baik secara individu, kelompok maupun masyarakat untuk meningkatkan kesadaran akan nilai K3 dan pencegahannya sehingga dengan sadar mau mengubah perilakunya menjadi perilaku sehat (Bajuri, 2016). Sedangkan dalam aspek keselamatan dan kesehatan kerja, K3 menyatakan bahwa penyuluhan K3 adalah bentuk usaha yang dilakukan untuk mendorong dan menguatkan kesadaran dan perilaku pekerja tentang K3 sehingga dapat melindungi pekerja, property, dan lingkungan.

Penyuluhan K3 bertujuan untuk membantu driver ojek online untuk sadar dan secara mandiri dapat melindungi diri mereka dari potensi bahaya pekerjaan. Penyuluhan dapat meningkatkan pengetahuan, sikap, tindakan aman saat bekerja dengan mengadakan pelatihan dan menyediakan APD yang mereka butuhkan. Penyediaan APD bertujuan untuk meningkatkan perubahan perilaku pada pemulung, karena tanpa adanya fasilitas mendukung akan memperlambat proses perubahan perilaku. Derajat keselamatan dan kesehatan driver ojek yang semakin meningkat pada akhirnya akan meningkatkan produktivitas mereka. Tujuan pengabdian masyarakat adalah meningkatkan pengetahuan dan sikap dalam meningkatkan derajat keselamatan dan kesehatan untuk meningkatkan produktivitas.

\section{BAHAN DAN METODE}

Pada kegiatan pengabdian pada masyarakat ini dimana penerapan IPTEKnya berupa mendapatkan pengetahuan dan sikap aman saat bekerja pada driver ojek online untuk mencegah kecelakaan dan penyakit akibat kerja. Alat dan bahan yang digunakan antara lain laptop, infokus, layar proyektor, dan laptop. Dalam kegiatan ini dimana sasaran yang 
akan dilakukan pada pada driver ojek online sebanyak 20 orang dimana dilakukan dalam dua sesi bertujuan untuk mengikuti program pemerintah dalam menekan angka kejadian covid-19. Satu sesi terdiri atas 10 orang. Dalam kegiatan pengabdian pada masyarakat ini dilakukan pemberian penyuluhan yaitu pemaparan materi tentang pengertian ojek online, pengertian keselamatan dan kesehatan kerja (K3) pada pekerja ojek online, tujuan penerapan K3 pada driver ojek online, risiko kesehatan yang mungkin diderita oleh pekerja ojek online, berkendara ergonomis, berkendaraan aman dan cara menghindari risiko penyakit pada pekerja ojek online. Dalam pengabdian pada masyarakat ini dilakukan evaluasi setelah kegiatan dilakukan. Evaluasi yang dilakukan yaitu dengan membandingkan hasil pengetahuan dan sikap sebelum dan sesudah dilakukannya penyuluhan ataupun pengabdian masyarakat, dengan demikian didapatkan nantinya apakah kegiatan pengabdian pada masyarakat tersebut berhasil dilakukan. Pelaksanaan kegiatan pengabdian masyarakat ini dilakukan sekitar 90 menit/sesi dalam pelaksanaannya.

\section{HASIL DAN PEMBAHASAN}

Gambaran umum responden dalam pengabdian ini antara lain usia, jenis kelamin dan pendidikan sebagaimana terlihat pada Tabel 1 .

Tabel 1 Distribusi Frekuensi Berdasarkan Umur, Jenis Kelamin, dan Pendidikan Driver Ojek Online

\begin{tabular}{lcc}
\hline Karakteristik & n & \% \\
\hline Umur Responden & & \\
\hline 21-24 tahun & 2 & 10,0 \\
25-28 tahun & 3 & 15,0 \\
29-32 tahun & 5 & 25,0 \\
33-36 tahun & 4 & 20,0 \\
37-40 tahun & 3 & 15,0 \\
41-45 tahun & 3 & 15,0 \\
\hline Jenis Kelamin & & \\
\hline Laki-Laki & 20 & 100.0 \\
Perempuan & 0 & 0,0 \\
\hline Pendidikan & & \\
\hline SMA & 13 & 35,0 \\
Perguruan Tinggi & 7 & $\mathbf{1 0 0 . 0}$ \\
\hline Jumlah & $\mathbf{4 0}$ &
\end{tabular}


Berdasarkan Tabel 1. dapat diketahui bahwa mayoritas driver ojek online berusia 2932 tahun sebanyak 5 orang $(25,0 \%)$ dan minoritas berusia $21-24$ tahun sebanyak 2 orang $(10,0 \%)$. Semua responden berjenis kelamin laki-laki sebanyak 20 orang $(100,0 \%)$. Pendidikan responden mayoritas SMA sebanyak 13 orang $(65,0 \%)$.

Gambaran pengetahuan driver ojek online sebelum dilakukan penyuluhan ditemukan sebanyak 6 orang $(30 \%)$ yang memiliki pengetahuan baik dan setelah dilakukan penyuluhan pengetahuan baik mengalami kenaikan yaitu menjadi 17 orang (85\%). Hasil lengkapnya dapat dilihat pada Gambar 1.

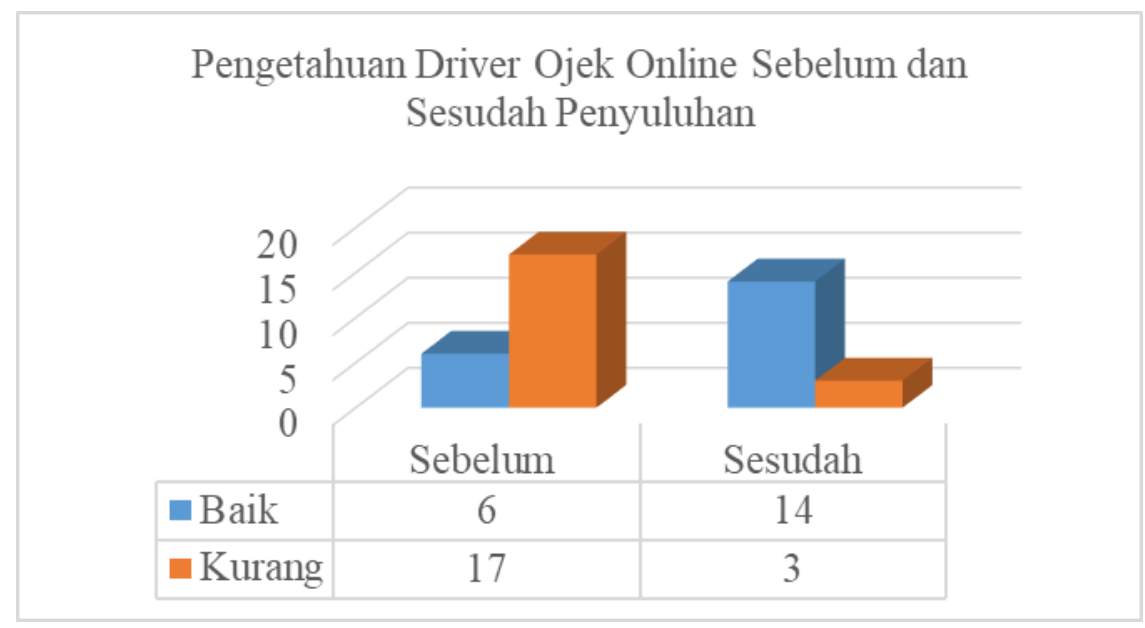

Gambar1. Grafik Pengetahuan Driver Ojek Online Sebelum dan Sesudah Penyuluhan

Gambaran sikap driver ojek online sebelum dilakukan penyuluhan ditemukan sebanyak 15 orang (75\%) yang memiliki sikap positif dan setelah dilakukan penyuluhan sikap positif mengalami kenaikan yaitu menjadi 20 orang (100\%). Hasil lengkapnya dapat dilihat pada Gambar 2.

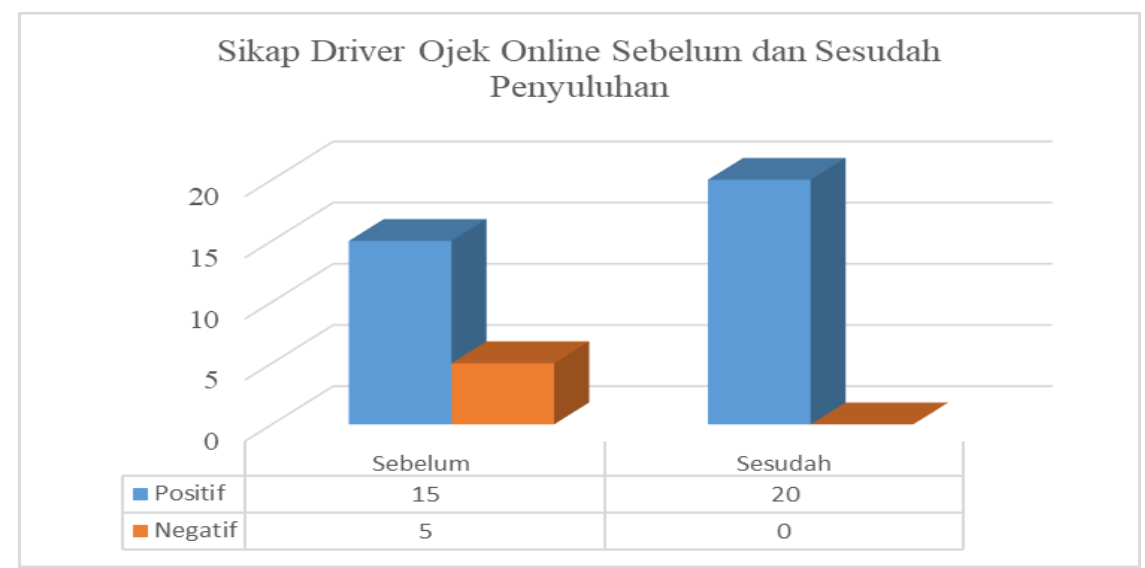

Gambar2. Grafik Sikap Driver Ojek Online Sebelum dan Sesudah Penyuluhan 
Hasil menunjukkan bahwa terdapat kenaikan pengetahuan dan sikap setelah dilakukan penyuluhan. Hal ini disimpulkan bahwa dengan pemberian informasi memang sangat efektif dalam meningkatkan pengetahuan seseorang. Pada saat dilakukan pengabdian masyarakat kebanyakan dari peserta tidak mengetahui tentang keselamatan dan kesehatan kerja, mereka juga baru pertama kali mendapatkan informasi mengenai MSDS istilah dalam masyarakat ada nyeri punggung baik punggung atas maupun punggung bawah. Peserta juga menyatakan sering mengalami keluhan punggung mereka berfikir itu hanya akibat dari berkendara yang terlalu lama, dan mereka baru mengetahui bahwa nyeri punggung juga dapat disebabkan karena salah duduk atau posisi duduk saat berkendara tidak ergonomik. Saat mereka menahan rasa sakit mereka rata-rata menyatakan agak sedikit menekuk badan mereka ke arah depan padahal itu merupakan posisi yang sangat salah dalam berkendara menggunakan sepeda motor.

Pada saat kegiatan tersebut juga dipraktekkan posisi cara berkendara yang tepat agar otot-otot punggung tidak mudah bergeser yang menyebabkan rasa yang kurang nyaman dan merasa cepat capek di area punggung bawah atau atas akibat posisi yang salah, ditambah dengan tubuh yang dehidrasi. Driver ojek menyatakan jarang minum selama bekerja karena tidak ingat, biaya air untuk minum mahal, tidak bawa air putih dari rumah, dan lebih senang mengkonsumsi minuman dingin sehingga dahaga cepat terasa hilang. Peserta juga diberikan penjelasan bahwa pentingnya mengkonsumsi air putih secara rutin agar sirkulasi darah lancar bukan hanya melepas dahaga saja sehingga kesehatan para driver tetap terjaga dan dapat terus berproduktivitas. Para driver juga menyatakan bahwa selama ini tidak semua driver menggunakan masker, karena ada beberapa driver yang menyatakan bahwa diri mereka pria dan biasanya yang menggunakan masker itu adalah wanita yang takut terkena panas, tetapi semenjak terjadinya pandemi covid-19 ini mereka menyatakan harus menggunakan masker saat berkendara. Padahal alat pelindung diri seperti masker dapat mengurangi serapan polusi yang masuk ke dalam tubuh kita dan penggunaan sarung tangan, jaket dan celana panjang dapat mengurangi paparan sinar UV dari sinar matahari yng dapat menyebabkan kulit terbakar dan dalam jangka waktu yang lama dapat menyebabkan kanker

Penyuluhan pada pekerja informal merupakan salah satu cara dalam menyebarkan perilaku aman saat bekerja bukan hanya saat bekerja di perusahaan atau pabrik sehingga terjadi sinergi antara pekerja formal dan pekerja informal karena setiap pekerja memiliki hak untuk memperoleh hidup yang aman saat bekerja, dimanapun tempat mereka bekerja. Dengan adanya pemberian informasi ini para driver dapat secara mandiri untuk berperilaku 
aman dan sehat saat bekerja dan juga dapat penerus informasi kepada rekan driver ojek lainnya yang tidak ikut dalam kegiatan ini.

\section{KESIMPULAN DAN SARAN}

Kesimpulan dalam kegiatan ini adalah penyuluhan keselamatan dan kesehatan kerja mampu meningkatkan pengetahuan dan sikap pekerja pada driver ojek online agar mandiri dan senantiasa mempraktekkan perilaku aman saat bekerja sehingga dapat berproduktivitas dalam kondisi yang selalu sehat.

Saran dalam kegiatan ini diharapkan kepada driver ojek online yang telah megikuti kegiatan ini dapat menyebarkan informasi ini ke rekan sejawat lainnya dan bagi pihak lain yang berkonsentrasi dalam bidang $\mathrm{k} 3$ dapat bersama-sama mendidik masyarakat pekerja informal agar semua pekerja tetap sehat dan terus berproduktivitas.

\section{UCAPAN TERIMAKSIH}

Saya ucapkan terimaksih kepada para komunitas driver ojek online yang telah bersedia mengikuti kegiatan ini dan juga terikasih kepada Institut Kesehatan Helvetia yang mendukung acara kegiatan ini.

\section{DAFTAR PUSTAKA}

Afrianto, D. (2014). Pengaruh Penyuluhan terhadap Pengetahuan, Sikap dan Tindakan Petani Paprika di Desa Kumbo-Pasuruan terkait Penggunaan Alat Pelindung Diri (APD) dari Bahaya Pestisida Tahun 2014. JOUR.

Bajuri, Z. (2016). Intervensi Penyuluhan Menggunakan Media Lembar Balik terhadap Peningkatan Pengetahuan tentang Bahaya Keselamatan dan Kesehatan Kerja (K3) dan Pencegahannya pada Pekerja Las di Ciputat Kelurahan Pisangan (Skripsi). FKIK UIN Jakarta.

Burke, M. J., Salvador, R. O., Smith-Crowe, K., Chan-Serafin, S., Smith, A., \& Sonesh, S. (2011). The dread factor: How hazards and safety training influence learning and performance. Journal of Applied Psychology, 96(1), 46. JOUR.

Dwi Lestari, Y. (2018). Analisis Faktor Kesehatan dan Keselamatan Kerja (K3) yang Mempengaruhi Kecelakaan Kerja di PT. Semen Padang. Politeknik Negeri Padang.

Ferusgel, A., Masni, M., \& Arti, N. A. (2019). Faktor yang Mempengaruhi Risiko Musculoskeletal Disoders (MSDs) pada Driver Ojek Online Wanita Kota Medan. Jurnal Penelitian Kesehatan "SUARA FORIKES”(Journal of Health Research" Forikes Voice”), 11(1), 68-72. JOUR.

Kalalo, S. Y. (2016). Hubungan antara Pengetahuan dan Sikap tentang K3 dengan Kejadian Kecelakaan Kerja pada Kelompok Nelayan di Desa Belang Kecamatan Belang Kabupaten Minahasa Tenggara. Pharmacon, 5(1). JOUR.

Notoatmodjo, S. (2007). Promosi kesehatan dan ilmu perilaku. JOUR.

RI, K. Undang-Undang Tahun 1970 tentang Keselamatan Kerja, Sekretariat Negara. Jakarta $\S(1 \mathrm{AD})$. JOUR. 
Salindeho, M. A., Kawatu, P. A. T., \& Joseph, W. B. S. (2017). Analisis Potensi Bahaya pada Pekerjaan dengan Menggunakam Metode Job Safety Analysis (JSA) pada Proses Pengolahan Kelapa Sawit PT Sinergi Perkebunan Nusantara Kabupaten Morowali Utara Provinsi Sulawesi Tengah. Media Kesehatan, 9(3). JOUR. 